\title{
Predictors of Postoperative Atrial Fibrillation
}

\section{After Abdominal Surgery and Insights from Other Surgery Types}

\author{
Christoffer Valdorff \\ Madsen (iD) ${ }^{1,2}$ \\ Lars Nannestad Jørgensen (iD ${ }^{3}$ \\ Bonna Leerhøy iD ${ }^{3}$ \\ Ismail Gögenur ${ }^{4}$ \\ Sarah Ekeloef $\mathbb{D D}^{4}$ \\ Ahmad Sajadieh' \\ Helena Domínguez ${ }^{1,2}$ \\ 'Department of Cardiology, Bispebjerg- \\ Frederiksberg Hospital, Frederiksberg, \\ Denmark; ${ }^{2}$ Department of Biomedical \\ Science, Copenhagen University, \\ Copenhagen, Denmark; ${ }^{3}$ Digestive \\ Disease Center, Bispebjerg Hospital, \\ Copenhagen, Denmark; ${ }^{4}$ Department of \\ Surgery, Zealand University Hospital, \\ Køge, Denmark
}

This article was published in the following Dove Press journal: Research Reports in Clinical Cardiology

\begin{abstract}
Postoperative atrial fibrillation (POAF) in relation to abdominal surgery can cause clinical deterioration, prolonged hospitalization, admittance to intensive care units, stroke and increased mortality. The current review focus on patients developing POAF in relation to abdominal surgery and aims to present the current knowledge on predictors of this condition. Furthermore, predictors identified in other surgical populations that may be transferable and guide future research within the field of abdominal surgery will be presented. A systematic literature search of patients undergoing abdominal surgery and developing POAF was performed on PubMed and Embase. All types of study interventions, comparators and designs were included. All studies included reported POAF as primary or secondary outcome. All peer-reviewed English full-text manuscripts regardless of publication date were included. We included five studies out of the 149 unique records identified. Age, congestive heart failure, hypertension, vascular disease and surgical approach are risk factors associated with the development of POAF. Furthermore, inflammation biomarkers, dobutamine stress echocardiography and cardiac single-photon emission computed tomography can predict POAF. Insights from other surgical cohorts reveal that other biomarkers (ie, brain natriuretic peptide (BNP) and N-terminal pro-BNP), electrocardiography and echocardiography can be used to predict POAF and may be applied in future research projects within the field of abdominal surgery. In conclusion, very scarce evidence is currently available in predicting POAF after abdominal surgery. However, predicting POAF seems possible and feasible, why the authors encourage readers to initiate new research to close the current
\end{abstract} knowledge gap and improve clinical management.

Keywords: postoperative atrial fibrillation, surgery, biomarkers, electrocardiogram, echocardiography, complications

\section{Introduction}

Postoperative atrial fibrillation (POAF) is defined as "new onset of atrial fibrillation (AF) (usually self-terminating) after major (typically cardiac) surgery in patients [...] with no prior history of AF". ${ }^{1}$ POAF also occur in $4-17 \%$ of patients undergoing abdominal surgery. ${ }^{2-5}$ The wide range represents a heterogenous population; procedures vary from elective colon cancer surgery with little cardiac comorbidity $(4.4 \%)$ to emergency abdominal surgery in patients with known cardiac comorbidity (stable coronary artery disease) $(17.2 \%) .^{2-5}$ Furthermore, there are issues regarding surgical approach (open vs laparoscopic), method of diagnosing POAF (clinical symptoms, noted by clinical staff, 12-lead ECG with AF at one time point,
Correspondence: Helena Domínguez Frederiksberg Hospital, Nordre Fasanvej 57, Frederiksberg 2000, Denmark Tel +4538166068

Fax +4522989343

Email mdom0002@regionh.dk 
sustained or repetitive arrhythmia/AF, etc.) and additional comorbidities. ${ }^{4}$ POAF is associated with increased risk of hemodynamic instability, heart failure, pulmonary edema, stroke and mortality. Prediction and early diagnosis of POAF after abdominal surgery might lead to less postoperative complications, reduced length of hospitalization and prevention of admittance to Intensive Care Unit, which is important for both patients and community. ${ }^{2-6}$ The most recent guidelines from the European and American Societies of Cardiology have no specific recommendation regarding management of POAF. ${ }^{1,7}$ In some cases, surgeons may refer patients to an outpatient cardiology clinic for further diagnostic examinations. However, this current practice potentially delays treatment and increases the risk of complications. ${ }^{8,9}$

Current risk-stratification models for POAF after nonabdominal surgery primarily rely on clinical data, ie, demography and comorbidities. ${ }^{10,11}$ Addition of preoperative paraclinical information such as biomarkers in blood or urine, electrocardiograms (ECGs) or cardiac imaging might improve the predictive abilities. ${ }^{12,13}$ A robust model able to predict POAF could improve clinical management of patients undergoing abdominal surgery. ${ }^{4,5}$ The review objective is to present an overview of the current knowledge on predictors of POAF in relation to abdominal surgery, including lessons from other types of surgery, to aid clinicians and encourage future research projects.

\section{Methods}

The review was based on a systematic literature search of studies presenting data on patients undergoing abdominal surgery and developing POAF. All types of study interventions, comparators and designs were included. All studies included reported POAF as primary or secondary outcome. All peer-reviewed published English full-text papers were included regardless of publication date. PubMed and Embase were searched for the following MeSH terms: ((surgery (as defined below) AND atrial fibrillation) AND (predict)). The following types of surgery were included general, abdominal, gastrointestinal, gastric, duodenal, colonic, colorectal, and rectal. The latest search was performed on 26 September 2019.

After acquisition of the full literature list, duplicates were removed (Figure 1). Abstracts were subsequently screened for eligibility by relevance of population and outcome. Eligible studies included patients undergoing abdominal surgery (as defined above) and presented the prediction of POAF as the primary or secondary outcome.
Studies were labelled with "other outcome" if they did not present POAF as primary or secondary outcome, and with "other population" if they did not include any patients undergoing abdominal surgery; both of which led to exclusion from the current review. Protocols and editorials were excluded. No quantitative analysis was performed.

\section{Results}

The literature review revealed a total of 205 records of which five were eligible for qualitative synthesis (Figure 1). Two studies were insufficiently described for evaluation and one relevant study was identified via reference lists (Figure 1).

Studies were heterogenous in both population sampling and methods applied (Table 1). Studies included patients undergoing a variety of surgery; from colorectal cancer surgery, to liver transplantation, and general (non-specified) abdominal surgery (Table 1). Preoperative AF was primarily excluded by review of patients' medical history or a single preoperative ECG. Two studies (Alonso-Coello et al and Nicolau-Raducu et al) did not describe exclusion of patients with preoperative AF. Two studies applied postoperative ECGs in attempt to diagnose asymptomatic POAF, while three studies did not; no studies have used postoperative continuous heart rhythm monitoring.

Based on two studies ( $\mathrm{N}=563$ and $\mathrm{N}=2970)$, patients undergoing abdominal surgery have an increased risk of developing POAF if they are older (OR 1.03 [CI 1.011.06]), have congestive heart failure (OR 3.04 [CI 1.884.92]), hypertension (OR 1.72 [CI 1.19-2.51]), or vascular disease (OR 2.29 [CI 1.39-3.37]), and if they undergo open (vs laparoscopic) surgery (OR 3.3 [CI 1.3-8.0]) (Table 1). ${ }^{5,14}$ One study has developed a simple risk-prediction model for POAF based on information of age and type of surgery. ${ }^{15}$ The risk-prediction model includes age-interval (65-74 years (two points), 75-84 years (three points) or $>85$ years (four points)) and surgery type (Intra-abdominal (one point), major vascular (two points), or intrathoracic surgery (three points)). Points correspond to one of four categories with incidence of POAF ranging from $0.5 \%$ to $5.3 \%$ (C statistics 0.69 , goodness-of-fit test $\mathrm{p}=0.87){ }^{15}$

One study examined pre- and postoperative levels of C-reactive protein (CRP) and interleukin-6 (IL-6) and the association with POAF. ${ }^{16}$ High levels of IL-6 (>432 pg/ $\mathrm{mL}$ ) at day 1 after surgery were associated with an extensive composite endpoint of different complications (mortality, pneumonia, sepsis, anastomotic dehiscence, wound infection, noncardiac respiratory failure, AF, congestive 


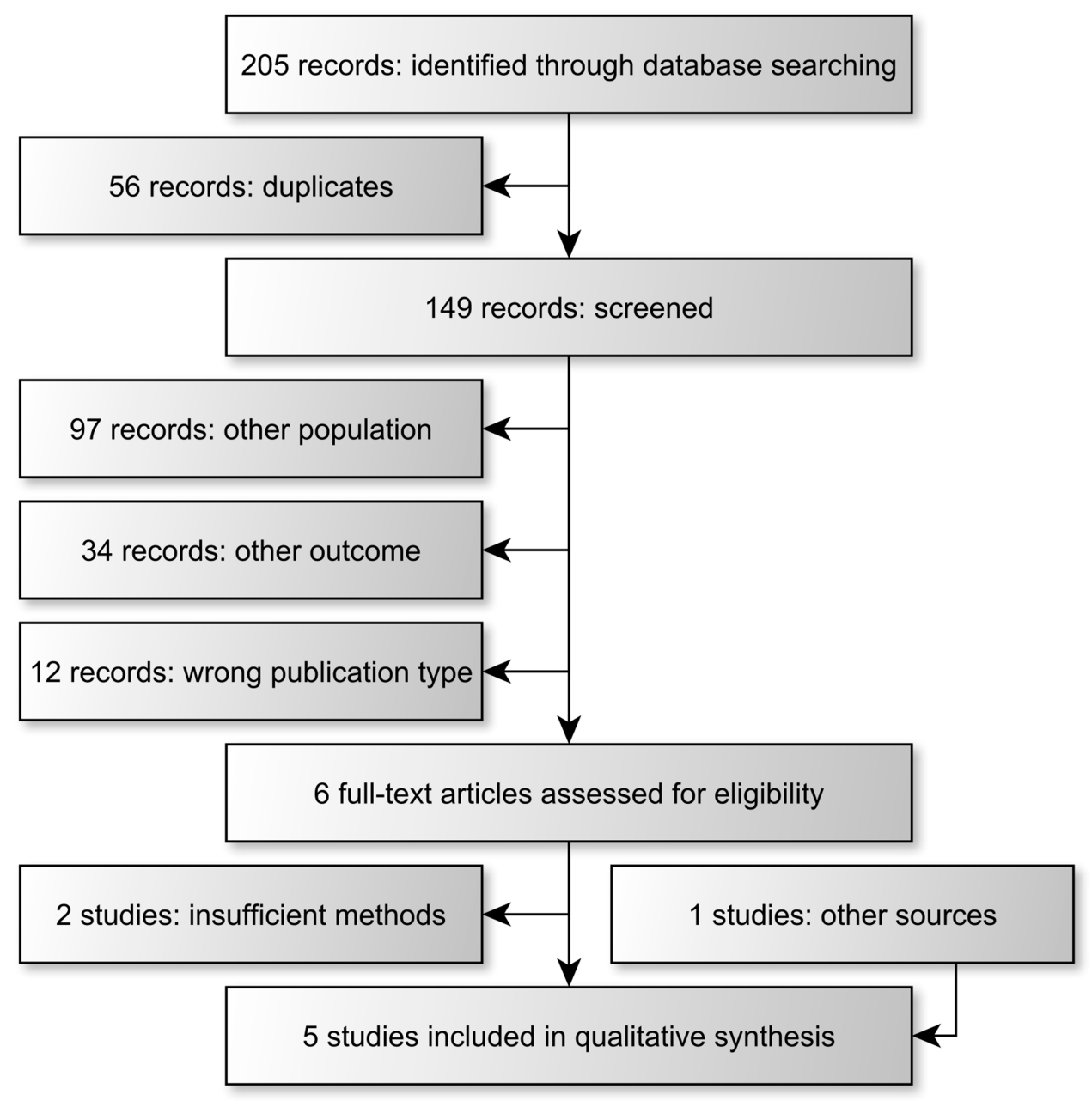

Figure I Flow diagram of study selection. "Other population", indicates non-abdominal surgery as defined in the methods, "Other outcome", is studies reporting not reporting POAF as primary or secondary outcome, "Wrong publication type" indicates abstracts, guidelines and editorials.

heart failure, myocardial infarction, and reoperation within 30 days of surgery) (OR 3.3 [CI 1.3-8.5]) but not independently with POAF.16 Preoperative values of CRP and IL-6 were not associated with clinical complications or POAF incidence (Table 1). ${ }^{16}$

One study used imaging modalities to predict POAF in an abdominal surgical population. Low rate blood pressure product $(<11,700)$ in dobutamine stress echocardiography was associated with POAF ( $\mathrm{p}=0.002)$ in a single prospective study including 389 patients undergoing liver transplantation. ${ }^{17}$ Cardiac single-photon emission computed tomography (cardiac SPECT) was used to predict POAF with a negative predictive value of $91 \%$, positive predictive value of $28 \%$, sensitivity of $57 \%$, and specificity of $75 \%$, in a subgroup of 47 patients (Table 1). ${ }^{17}$

No studies have used cardiac magnetic resonance imaging (cMRI), urinary biomarkers or ECGs indices to predict POAF after abdominal surgery.

\section{Discussion}

Literature on the development of POAF in patients undergoing abdominal surgery is limited. In total, five studies were identified reporting data on clinical risk-factors, inflammation biomarkers, dobutamine stress echocardiography and cardiac SPECT. Data are currently insufficient to provide clinical guidelines for prediction of POAF after abdominal surgery. POAF has been extensively investigated in nonabdominal surgical populations and insight from these studies might be transferred to patients undergoing abdominal surgery and applied in future studies.

\section{Clinical Risk-Factors and Prediction Models}

Clinical risk-factors in patients undergoing abdominal surgery are comparable to those patients undergoing other types of surgery; eg, age, hypertension, congestive heart 
Table I Predictors of Postoperative Atrial Fibrillation in Abdominal Surgery

\begin{tabular}{|c|c|c|c|c|}
\hline & Study & Surgery Type & $\mathbf{N}$ & Findings Associated with POAF \\
\hline \multirow[t]{3}{*}{$\begin{array}{l}\text { Clinical risk } \\
\text { factors }\end{array}$} & Siu et al $2005^{14}$ & Colorectal cancer (elective) & 563 & $\begin{array}{l}\text { Open (vs laparoscopic) surgical approach (OR } 3.3[\mathrm{Cl} \\
\mathrm{I.3-8.0])}\end{array}$ \\
\hline & $\begin{array}{l}\text { Alonso-Coello } \\
\text { et al } 2017^{15}\end{array}$ & $\begin{array}{l}\text { General non-cardiac } \\
\text { (elective and emergent) }\end{array}$ & $\begin{array}{l}835 \text { I ( } 2 \text { II with atrial } \\
\text { fibrillation) }\end{array}$ & Age and surgery type $\mathrm{e}^{\#}$ \\
\hline & $\begin{array}{l}\text { Heywood et al } \\
2019^{5}\end{array}$ & $\begin{array}{l}\text { General abdominal (elective } \\
\text { and emergent) }\end{array}$ & $\begin{array}{l}2970 \text { ( } 187 \text { with atrial } \\
\text { fibrillation) }\end{array}$ & $\begin{array}{l}\text { Age (OR I.03 [Cl I.0I-I.06]) Congestive heart } \\
\text { failure (OR } 3.04[\mathrm{Cl} \text { I.88-4.92]) } \\
\text { Hypertension (OR I.72 [Cl I.I9-2.5। }] \text { ) } \\
\text { Vascular disease (OR } 2.29[\mathrm{Cl} \text { I.39-3.37]) }\end{array}$ \\
\hline Blood & Rettig et al $2016^{16}$ & $\begin{array}{l}\text { General abdominal (elective } \\
\text { and emergent) }\end{array}$ & 170 & CRP and IL-6 not associated \\
\hline Imaging & $\begin{array}{l}\text { Nicolau-Raducu } \\
\text { et al } 2015^{17}\end{array}$ & $\begin{array}{l}\text { Orthotopic liver } \\
\text { transplantation (elective) }\end{array}$ & 389 & $\begin{array}{l}\text { DSE blood pressure product }<11,970(P=0.002)^{*} \\
\text { Positive cardiac SPECT PPV } 28 \% \text { and NPV } 91 \%\end{array}$ \\
\hline
\end{tabular}

Notes: *Association, " results presented as risk-stratification model, see text.

Abbreviations: DBE, dobutamine stress echocardiography; SPECT, single-photon emission computed tomography; PPV, positive predictive value; NPV, negative predictive value.

failure, etc. ${ }^{9,15}$ No attempts have been made to create a prediction model for POAF after abdominal surgery exclusively; one model has included patients undergoing abdominal surgery, ${ }^{15}$ and several models have included patients undergoing cardiac surgery. ${ }^{10-12}$ A prediction model for patients undergoing abdominal surgery should consider the following clinical data: age, gender, congestive heart failure, renal function (chronic renal disease), pulmonary function (chronic obstructive pulmonary disease) and surgical attributes (eg, emergency vs elective, laparotomy vs laparoscopy, duration of surgery and organ system). Furthermore, addition of paraclinical data of left atrial (LA) size, PR-interval and QRS-duration have improved earlier risk-prediction models and should be considered. $^{10-12}$

\section{Blood Plasma Biomarkers}

Inflammation biomarkers were investigated in one abdominal surgical study and were not found to be associated with POAF. ${ }^{16}$ In non-cardiac thoracic surgery, similar conclusions were reached regarding both CRP and IL-6. ${ }^{18}$ In cardiac surgical populations, preoperative white blood cell count and CRP were able to predict POAF. ${ }^{19,20}$ Both blood samples are widely available and used in routine practice in patients undergoing abdominal surgery and might be beneficial to discriminate those patients developing POAF.

Brain natriuretic peptide (BNP) and N-terminal (NT) proBNP are other commonly investigated plasma biomarkers associated with the development of POAF. ${ }^{21-27}$ A review in non-cardiac thoracic surgical patients reported that preoperative elevated BNP and NT-pro-BNP were predictive of POAF after both esophagectomy and major lung recessions, but not after minor non-cardiac thoracic surgery. ${ }^{26}$ Likewise, several studies have found that elevated preoperative BNP predicted cardiac events including POAF in elective and emergency orthopedic surgery. ${ }^{21,22,28}$ Concerning cardiac surgery, a systematic review and meta-analysis found a moderate association between preoperative BNP and development of POAF. ${ }^{23}$ More recent prospective and retrospective studies of cardiac surgical populations have confirmed a positive association between elevated preoperative BNP and NT pro-BNP, and POAF. ${ }^{24,25,27,29,30}$ Hence, there is substantial evidence that preoperative levels of BNP and NT pro-BNP are associated with POAF in several nonabdominal surgical populations. Currently, no studies of abdominal surgical populations have used these biomarkers. Nonetheless, as these biomarkers are indicative of heart disease (especially heart failure) and are routinely used for screening in outpatient clinics, they could constitute interesting biomarkers for predicting POAF in an abdominal surgical population. One could speculate that it indeed is those patients with an early indicator of structural cardiac disease that develop POAF when undergoing surgery.

\section{Electrocardiograms}

No studies have investigated the predictive value of ECGs in abdominal surgery. However, several studies have been performed in other surgical populations and an ECG could 
potentially aid to identify patients developing POAF after abdominal surgery. Readily available ECG indexes associated with POAF are: increased PR-interval (>180 or 192 $\mathrm{ms}$ ), increased P-wave duration ( $>100$ or 110 or $120 \mathrm{~ms}$ ), and prolonged QRS interval ( $>118 \mathrm{~ms}){ }^{12,18,31,32}$ Several other ECG indexes are reported for the cardiac surgical population, such as $\mathrm{P}$-wave amplitude, $\mathrm{P}$-wave terminal force $(>40 \mathrm{~ms}$ and depth $>1 \mathrm{~mm}$, P-wave index and P-wave frontal axis, etc.); but, these indexes are less readily available and thus more difficult to apply in clinical practice. ${ }^{12,33-37}$ ECG is generally easily accessible and commonly used prior to abdominal surgery, hence, potentially a promising tool for identifying POAF. Upcoming prediction models in abdominal surgical populations should consider including ECG indexes such as PR-interval, P-wave duration and QRS-duration similarly to the model developed by $\mathrm{Gu}$ et al for patients undergoing cardiac surgery. ${ }^{12}$

\section{Imaging}

A single study has used dobutamine stress echocardiography in patients undergoing liver transplantation. ${ }^{17}$ Although results showed that a low rate blood pressure product (ie, poor myocardial response to dobutamine) could predict POAF, ${ }^{17}$ it is not a method that is readily available, nor applicable prior to emergency surgery.

Transthoracic echocardiography (TTE) without stress testing has been investigated in other surgical populations and might be transferable to an abdominal surgical population. A recent study performed in patients undergoing non-cardiac thoracic surgery demonstrated that increased LA volume index, reduced LA emptying fraction, and transmitral flow deceleration time were predictive of POAF. $^{38,39}$

Several prospective and retrospective studies have reported that a larger preoperative LA is associated with POAF after both cardiac valve surgery and CABG. ${ }^{40-47}$

More advanced TTE measurements, such as speckletracking and strain analysis of the LA, have recently been investigated in numerous cardiac surgical populations. ${ }^{44,48-52}$ Impaired LA strain has a higher sensitivity in the prediction of POAF compared with measurements focusing solely on dilatation of the LA. ${ }^{49,51,52}$ It should be noted that in cardiac surgery, the incidence of POAF is high (up to $60 \%$ of patients undergoing mitral valve surgery and $35 \%$ of patients undergoing $\mathrm{CABG})^{53,54}$ and all these patients must be considered to have some degree of structural abnormality upon referral for cardiac surgery.

As TTE is a fast and non-invasive examination, it could be an option for screening patients prior to abdominal surgery. Current theories suggest that a "substrate" and a "trigger" is required for the development of AF. TTE might be able to demonstrate structural changes of the heart, especially the LA, which constitutes the "substrate", while the surgery is the inevitable "trigger" (Figure 2). ${ }^{56}$

Cardiac SPECT was used in one study of patient undergoing liver transplantation and proved able to exclude patient developing POAF. ${ }^{17}$ As with dobutamine stress testing cardiac SPECT cannot be used in an acute setting

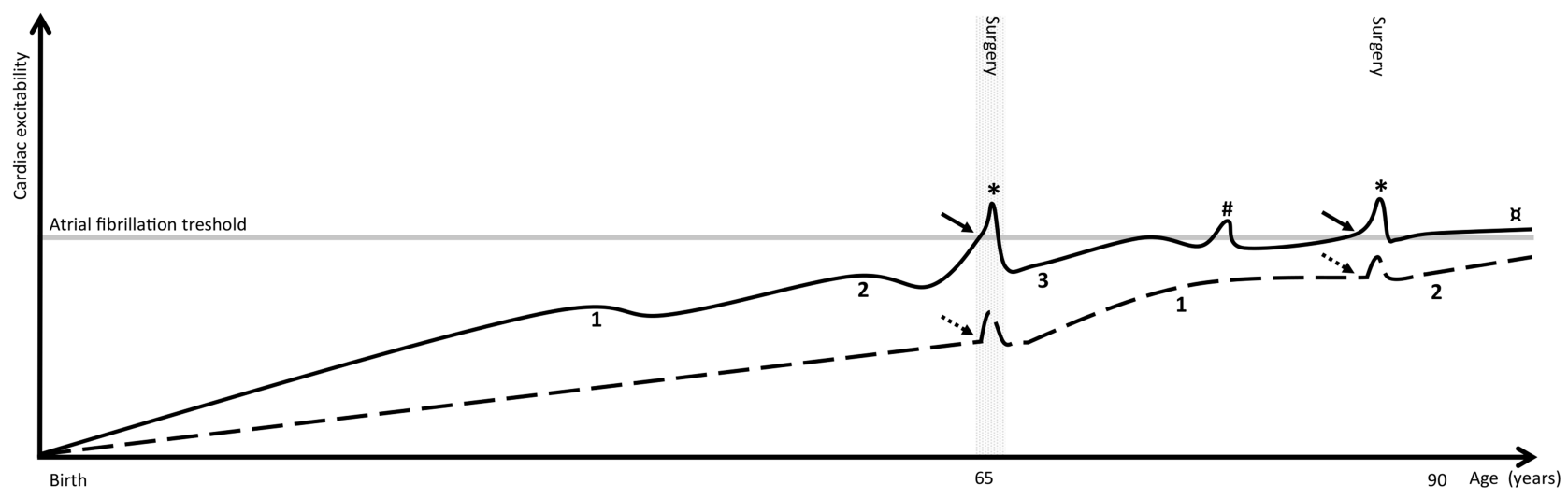

Figure 2 With age and comorbidities, "substrate" (ie, chronic inflammation, fibrosis, etc.) is increasing, and patients come closer to their atrial fibrillation (AF) threshold. Surgery might be the initial "trigger" for overt AF. AF is considered to become more frequent and self-sustaining with time, further increasing the "substrate". Comorbidities, eg, diabetes mellitus (I), hypertension (2), congestive heart failure (3). *POAF triggered by sympathetic activation, inflammation, oxidative stress, \# paroxysmal AF, apermanent AF. Arrows indicate potential times of assessment as in the current review, just prior to surgery. Evidence suggest that the difference between the black solid arrow and the dotted black arrow can be identified by blood sampling, electro- and echocardiograms. 
and is unlikely to be feasible for screening. To our knowledge, no studies of other surgical populations have used MRI or CT scanning to predict POAF.

\section{Predictors of POAF After Abdominal Surgery - Where are We Now and Where to Go}

Predicting POAF after abdominal surgery is currently difficult and evidence is scarce. The condition is relatively common, and the complications are potentially severe, why we believe that the condition deserves more attention. Current theories suggest that a cardiac "substrate" develops with age and comorbidities and is present prior to POAF. POAF might occur when patients with a "substrate" are exposed to the hemodynamic challenges of surgery and post-surgery inflammatory stress response (Figure 2). ${ }^{56}$

The incidence of POAF ranges from $4 \%$ to $17 \%$ in abdominal surgery. This variation cannot be explained solely by age and comorbidity; indeed, some patients with comorbidity will undergo surgery at an advanced age without developing POAF. Current data suggest that clinical outcome (eg, POAF vs no POAF) can be predicted by identifying structural and functional differences of the heart preoperatively, in patients that are otherwise comparable with regards to age, comorbidities and type of surgery. To predict POAF, it is likely that highest accuracy will be obtained through a combination of clinical and paraclinical data.

\section{Limitations}

The current review was limited by the unavailability of literature concerning the research question. The review only reported published journal manuscripts and reporting publication bias cannot be excluded. A general limitation was the heterogenicity of the studies that have investigated POAF after abdominal surgery. Definitions of POAF varied from study to study. Few studies have attempted to exclude pre-operative AF; ie, commonly a history without AF or an ECG with sinus rhythm prior to surgery has been deemed sufficient. No studies have applied ambulatory continuous heart rhythm monitoring preoperatively. Including patients with AF priori to surgery is an obvious limitation. Furthermore, peri- and postoperative continuous heart rhythm monitoring is not reported, and hence, identification of all cases of POAF are unlikely.

\section{Conclusion}

POAF frequently occur after abdominal surgery and leads to increased morbidity and mortality, meanwhile, clinical tools and guidelines are lacking. Limited evidence suggests that clinical risk-factors, inflammation biomarkers, dobutamine stress echocardiography and cardiac SPECT can identify patients developing POAF after abdominal surgery; however, lessons from other surgical populations suggest using additional plasma biomarkers (BNP, CRP, and IL-6, -8 and -10), ECG (prolonged P-wave, PR- and QRS-interval), and TTE indexes (LA size, volume and function). The authors encourage readers to initiate further research to close the current knowledge gap. Identifying patients at highest risk of developing POAF after abdominal surgery could lead to prevention of complications and better patient outcomes.

\section{Disclosure}

The authors report no conflicts of interest in this work.

\section{References}

1. Kirchhof P, Benussi S, Kotecha D, et al. 2016 ESC guidelines for the management of atrial fibrillation developed in collaboration with EACTS. Eur Heart J. 2016;37(2893):2962. doi:10.1016/j.rec. 2016.11.033

2. Bhave PD, Goldman LE, Vittinghoff E, Maselli J, Auerbach A. Incidence, predictors, and outcomes associated with postoperative atrial fibrillation after major noncardiac surgery. Am Heart $J$. 2012;164(6):918-924. doi:10.1016/j.ahj.2012.09.004

3. Devereaux PJ, Yang H, Yusuf S, et al. Effects of extended-release metoprolol succinate in patients undergoing non-cardiac surgery (POISE trial): a randomised controlled trial. Lancet. 2008;371:1839-1847. doi:10.1016/ S0140-6736(08)60601-7

4. Chebbout R, Heywood EG, Drake TM, et al. A systematic review of the incidence of and risk factors for postoperative atrial fibrillation following general surgery. Anaesthesia. 2018;73:490-498. doi:10.11 11/anae. 14118

5. Heywood EG, Drake TM, Bradburn M, Lee J, Wilson MJ, Lee MJ. Atrial fibrillation after gastrointestinal surgery: incidence and associated risk factors. J Surg Res. 2019;238:23-28. doi:10.1016/j. jss.2019.01.017

6. Polanczyk CA, Goldman L, Marcantonio ER, Orav EJ, Lee TH. Supraventricular arrhythmia in patients having noncardiac surgery: clinical correlates and effect on length of stay. Ann Intern Med. 1998;129(4):279-285. doi:10.7326/0003-4819-129-4-19980815000003

7. January CT, Wann LS, Calkins H, et al. 2019 AHA/ACC/HRS focused update of the $2014 \mathrm{AHA} / \mathrm{ACC} / \mathrm{HRS}$ guideline for the management of patients with atrial fibrillation ACC/AHA TASK FORCE MEMBERS. Heart Rhythm. 2019;16(8):e66-e93. doi:10.1161/CIR.0000000000 000665

8. Camm AJ, Kirchhof P, Lip GYH, et al. Guidelines for the management of atrial fibrillation The Task Force for the Management of Atrial Fibrillation of the Developed with the special contribution of the European Heart Rhythm Association. Europace. 2010;12(10):1360 1420. doi:10.1093/europace/euq350 
9. Frendl G, Sodickson AC, Chung MK, et al. 2014 AATS guidelines for the prevention and management of peri-operative atrial fibrillation and flutter (POAF) for thoracic surgical procedures. $J$ Thorac Cardiovasc Surg. 2014;148(3):e153-e193. doi:10.1016/j.jtcvs.2014.06.036.2014

10. Mariscalco G, Biancari F, Zanobini M, et al. Bedside tool for predicting the risk of postoperative atrial fibrillation after cardiac surgery: the POAF score. J Am Heart Assoc. 2014;3(2):e000752. doi:10.1161/JAHA.113.000752

11. Gecmen C, Babur Guler G, Erdogan E, et al. SYNTAX score predicts postoperative atrial fibrillation in patients undergoing on-pump isolated coronary artery bypass grafting surgery. Anatol J Cardiol. 2015:655-661. doi:10.5152/anatoljcardiol.2015.6483.

12. Gu J, Andreasen JJ, Melgaard J, et al. Preoperative electrocardiogram score for predicting new-onset postoperative atrial fibrillation in patients undergoing cardiac surgery. J Cardiothorac Vasc Anesth. 2017;31(1):69-76. doi:10.1053/j.jvca.2016.05.036

13. Alexandre J, Saloux E, Chequel M, et al. Preoperative plasma aldosterone and the risk of atrial fibrillation after coronary artery bypass surgery: a prospective cohort study. J Hypertens. 2016;34(12):24492457. doi:10.1097/HJH.0000000000001105

14. Siu C, Tung H, Chu K, Jim M, Lau C-P, Tse H-F. Prevalence and predictors of new-onset atrial fibrillation after elective surgery for colorectal cancer. Pace. 2005;28:S121-S123. doi:10.1111/j.15408159.2005.00024.x

15. Alonso-Coello P, Cook D, Xu SC, et al. Predictors, prognosis, and management of new clinically important atrial fibrillation after noncardiac surgery: a prospective cohort study. Anesth Analg. 2017;125 (1):162-169. doi:10.1213/ANE.0000000000002111

16. Rettig TTCD, Verwijmeren L, Dijkstra IIM, Boerma D, Van De Garde EMWE, Noordzij PGP. Postoperative interleukin-6 level and early detection of complications after elective major abdominal surgery. Ann Surg. 2016;263(6):1207-1212. doi:10.1097/SLA.0000000000001342

17. Nicolau-Raducu R, Gitman M, Ganier D, et al. Adverse cardiac events after orthotopic liver transplantation: a cross-sectional study in 389 consecutive patients. Liver Transpl. 2015;21(1):13-21. doi:10.1002/lt.23997

18. Amar D, Zhang H, Heerdt PM, Park B, Fleisher M, Thaler HT. Statin use is associated with a reduction in atrial fibrillation after noncardiac thoracic surgery independent of C-reactive protein. Chest. 2005;128 (5):3421-3427. doi:10.1378/chest.128.5.3421

19. Weymann A, Popov A-F, Sabashnikov A, et al. Baseline and postoperative levels of $\mathrm{C}$-reactive protein and interleukins as inflammatory predictors of atrial fibrillation following cardiac surgery: a systematic review and meta-analysis. Kardiol Pol. 2018;76(2):440 451. doi:10.5603/kp.a2017.0242

20. Jacob KA, Nathoe HM, Dieleman JM, Van Osch D, Kluin J, van Dijk D. Inflammation in new-onset atrial fibrillation after cardiac surgery: a systematic review. Eur J Clin Invest. 2014;44(4):402-428. doi:10.1111/eci.12237

21. Villacorta Junior H, de Castro IS, Godinho M, et al. B-type natriuretic peptide is predictive of postoperative events in orthopedic surgery. Arq Bras Cardiol. 2010;95(6):743-748. doi:10.1590/S0066-782X 2010005000131

22. Vetrugno L, Langiano N, Gisonni R, et al. Prediction of early postoperative major cardiac events after elective orthopedic surgery: the role of B-type natriuretic peptide, the revised cardiac risk index, and ASA class. BMC Anesthesiol. 2014;14:1-9. doi:10.1186/1471-2253-14-20

23. Litton E, Ho KM. The use of pre-operative brain natriuretic peptides as a predictor of adverse outcomes after cardiac surgery: a systematic review and meta-analysis. Eur J Cardiothorac Surg. 2012;41(3):525534. doi:10.1093/ejcts/ezr007

24. Hernández-Leiva E, Dennis R, Isaza D, Umaña JP. Hemoglobin and B-type natriuretic peptide preoperative values but not inflammatory markers, are associated with postoperative morbidity in cardiac surgery: a prospective cohort analytic study. J Cardiothorac Surg. 2013;8(1):170. doi:10.1186/1749-8090-8-170
25. Masson S, Wu JHY, Simon C, et al. Circulating cardiac biomarkers and postoperative atrial fibrillation in the OPERA trial. Eur J Clin Invest. 2014;45(2):170-178. doi:10.1111/eci.12393

26. Toufektzian L, Zisis C, Balaka C, Roussakis A. Effectiveness of brain natriuretic peptide in predicting postoperative atrial fibrillation in patients undergoing non-cardiac thoracic surgery. Interact Cardiovasc Thorac Surg. 2015;20(1):654-657. doi:10.1093/icvts/ivu454

27. Bernstein E, Block R, Veazie P, Tompkins C, Allen Bashour C, Turan A. Preoperative brain natriuretic peptide and atrial arrhythmias after coronary artery bypass graft surgery. J Cardiothorac Vasc Anesth. 2015;29(3):611-616. doi:10.1053/j.jvca.2014.11.015

28. Chong CP, Ryan JE, van Gaal WJ, et al. Usefulness of N-terminal pro-brain natriuretic peptide to predict postoperative cardiac complications and long-term mortality after emergency lower limb orthopedic surgery. Am J Cardiol. 2010;106(6):865-872. doi:10.1016/j. amjcard.2010.05.012

29. Samy K, Anouar J, Mnif E, Imed F, Fatma A, Abdelhamid K. Nterminal pro-brain natriuretic peptide identifies patients at risk for occurrence of postoperative atrial fibrillation in cardiac surgery with cardiopulmonary bypass. Ann Card Anaesth. 2012;15(3):199-205. doi:10.4103/0971-9784.97976

30. Hernández-Romero D, Vílchez JA, Lahoz Á, et al. High-sensitivity troponin $\mathrm{T}$ as a biomarker for the development of atrial fibrillation after cardiac surgery. Eur J Cardiothorac Surg. 2014;45(4):733-738. doi:10.1093/ejcts/ezt488

31. Chang CM, Lee SH, Lu MJ, et al. The role of $\mathrm{P}$ wave in prediction of atrial fibrillation after coronary artery surgery. Int J Cardiol. 1999;68 (3):303-308. doi:10.1016/S0167-5273(98)00301-5

32. Passman R, Beshai J, Pavri B, Kimmel S. Predicting post-coronary bypass surgery atrial arrhythmias from the preoperative electrocardiogram. Am Heart J. 2001;142(5):806-810. doi:10.1067/mhj.2001. 118736

33. Rader F, Costantini O, Jarrett G, et al. Quantitative electrocardiography for predicting postoperative atrial fibrillation after cardiac surgery. $J$ Electrocardiol. 2011;44(6):761-767. doi:10.1016/j.jelectrocard.2010. 12.005

34. Wong JK, Lobato RL, Pinesett A, Maxwell BG, Mora-Mangano CT, Perez MV. P-wave characteristics on routine preoperative electrocardiogram improve prediction of new-onset postoperative atrial fibrillation in cardiac surgery. J Cardiothorac Vasc Anesth. 2014;28 (6):1497-1504. doi:10.1053/j.jvca.2014.04.034

35. Ovreiu M, Nair BG, Xu M, et al. Electrocardiographic activity before onset of postoperative atrial fibrillation in cardiac surgery patients. Pacing Clin Electrophysiol. 2008;31(11):1371-1382. doi:10.1111/ pace.2008.31.issue-11

36. Çetin M, Kocaman SA, Erdoğan T, et al. Fragmented QRS may predict postoperative atrial fibrillation in patients undergoing isolated coronary artery bypass graft surgery. Anatol J Cardiol. 2012;12 (7):576-583. doi:10.5152/akd.2012.184

37. Gang Y, Hnatkova K, Mandal K, Ghuran A, Malik M. Preoperative electrocardiographic risk assessment of atrial fibrillation after coronary artery bypass grafting. J Cardiovasc Electrophysiol. 2004;15 (12):1379-1386. doi:10.1046/j.1540-8167.2004.04084.x

38. Brecher O, Gulati H, Roistacher N, et al. Preoperative echocardiographic indices of diastolic dysfunction and brain natriuretic peptide in predicting postoperative atrial fibrillation after noncardiac surgery. Anesth Analg. 2017;124(4):1099-1104. doi:10.1213/ANE.00000000 00001471

39. Raman T, Roistacher N, Liu J, et al. Preoperative left atrial dysfunction and risk of postoperative atrial fibrillation complicating thoracic surgery. J Thorac Cardiovasc Surg. 2012;143(2):482-487. doi:10.10 16/j.jtcvs.2011.08.025

40. Açil T, Cölkesen Y, Türköz R, et al. Value of preoperative echocardiography in the prediction of postoperative atrial fibrillation following isolated coronary artery bypass grafting. Am J Cardiol. 2007;100 (9):1383-1386. doi:10.1016/j.amjcard.2007.06.025 
41. Naito Y, Yamazaki K. Preoperative left atrial volume index predicts postoperative atrial fibrillation in patients with severe aortic valve stenosis. J Anesth. 2013;27(5):699-704. doi:10.1007/s00540-0131594-8

42. Özlü MF, Erdem K, Kiriş G, et al. Predictive value of total atrial conduction time measured with tissue Doppler imaging for postoperative atrial fibrillation after coronary artery bypass surgery. J Interv Card Electrophysiol. 2013;37(1):27-33. doi:10.1007/s10840-012-9756-4

43. Pena E, Padro T, Molins B, Vilahur G, Badimon L. Proteomic signature of thrombin-activated platelets after in vivo nitric oxide-donor treatment: coordinated inhibition of signaling (phosphatidylinositol 3-kinasegamma, 14-3-3zeta, and growth factor receptor-bound protein 2) and cytoskeleton protein tran. Arter Thromb Vasc Biol. 2011;31(11):2560 2569. doi:10.1161/ATVBAHA.111.231852

44. Ozben B, Akaslan D, Sunbul M, et al. Postoperative atrial fibrillation after coronary artery bypass grafting surgery: a two-dimensional speckle tracking echocardiography study. Heart Lung Circ. 2016;25 (10):993-999. doi:10.1016/j.hlc.2016.02.003

45. Sabry A-S, Mansour H-K, El-Azm T, Mostafa S, Zahid B. Echocardiographic predictors of atrial fibrillation after mitral valve replacement. Egypt Heart J. 2017;69(4):281-288. doi:10.1016/j. ehj.2017.07.002

46. Kang M-K-K, Joung B, Shim CY, et al. Post-operative left atrial volume index is a predictor of the occurrence of permanent atrial fibrillation after mitral valve surgery in patients who undergo mitral valve surgery. Cardiovasc Ultrasound. 2018;16(1):5. doi:10.1186/ s12947-018-0123-1

47. Magne J, Salerno B, Mohty D, et al. Echocardiography is useful to predict postoperative atrial fibrillation in patients undergoing isolated coronary bypass surgery: a prospective study. Eur Heart J Acute Cardiovasc Care. 2019;8(2):104-113. doi:10.1177/2048872616688419

48. Candan O, Ozdemir N, Aung SM, et al. Left atrial longitudinal strain parameters predict postoperative persistent atrial fibrillation following mitral valve surgery: a speckle tracking echocardiography study. Echocardiography. 2013;30(9):1061-1068. doi:10.1111/echo.12222
49. Cameli M, Lisi M, Reccia R, et al. Pre-operative left atrial strain predicts post-operative atrial fibrillation in patients undergoing aortic valve replacement for aortic stenosis. Int $J$ Cardiovasc Imaging. 2014;30(2):279-286. doi:10.1007/s10554-013-0323-6

50. Başaran Ö, Tigen K, Gözübüyük G, et al. Predictive role of left atrial and ventricular mechanical function in postoperative atrial fibrillation: a two-dimensional speckle-tracking echocardiography study. Turk Kardiyol Dern Ars. 2016;44(1):45-52. doi:10.5543/tkda. 2015.11354

51. Verdejo HE, Becerra E, Zalaquet R, et al. Atrial function assessed by speckle tracking echocardiography is a good predictor of postoperative atrial fibrillation in elderly patients. Echocardiography. 2016;33 (2):242-248. doi:10.1111/echo.13059

52. Pessoa-Amorim G, Mancio J, Vouga L, et al. Impaired left atrial strain as a predictor of new-onset atrial fibrillation after aortic valve replacement independently of left atrial size. Rev Esp Cardiol. 2018;71(6):466-476. doi:10.1016/j.recesp.2017.09.020

53. Almassi G, Schowalter T, Nicolosi AC, et al. Atrial fibrillation after cardiac surgery: a major morbid event? Ann Surg. 1997;226(4):501513. doi:10.1097/00000658-199710000-00011

54. Maisel WH, Rawn JD, Stevenson WG. Atrial fibrillation after cardiac surgery. Ann Intern Med. 2001;135(12):1061-1073. doi:10.7326/ 0003-4819-135-12-200112180-00010

55. Lau DH, Linz D, Schotten U, Mahajan R, Sanders P, Kalman JM. Pathophysiology of paroxysmal and persistent atrial fibrillation: rotors, foci and fibrosis. Heart Lung Circ. 2017;26(9):887-893. doi:10.1016/j.hlc.2017.05.119

56. Melduni RM, Suri RM, Seward JB, et al. Diastolic dysfunction in patients undergoing cardiac surgery: a pathophysiological mechanism underlying the initiation of new-onset post-operative atrial fibrillation. J Am Coll Cardiol. 2011;58(9):953-961. doi:10.1016/j. jacc. 2011.05 .021
Research Reports in Clinical Cardiology

\section{Publish your work in this journal}

Research Reports in Clinical Cardiology is an international, peerreviewed, open access journal publishing original research, reports, editorials, reviews and commentaries on all areas of cardiology in the clinic and laboratory. The manuscript management system is

\section{Dovepress}

completely online and includes a very quick and fair peer-review system. Visit http://www.dovepress.com/testimonials.php to read real quotes from published authors. 